J. Dairy Sci. 95:7173-7185

http://dx.doi.org/10.3168/jds.2012-5839

(C) American Dairy Science Association ${ }^{\circledR}, 2012$.

\title{
Monitoring dry period intramammary infection incidence and elimination rates using somatic cell count measurements
}

\author{
S. Dufour ${ }^{\star} \dagger^{1}$ and I. R. Dohoo* $\dagger$ \\ ${ }^{*}$ Department of Health Management, Atlantic Veterinary College, University of Prince Edward Island, 550 University Ave., Charlottetown, \\ Prince Edward Island, C1A 4P3, Canada \\ †Canadian Bovine Mastitis Research Network, C.P. 5000, St-Hyacinthe, Quebec, J2S 7C6, Canada
}

\section{ABSTRACT}

The objective of the study was to evaluate the predictive ability of the herd dry period (DP) intramammary infection (IMI) incidence and elimination rates derived from predry and postcalving somatic cell count (SCC) measurements [quarter-level SCC and dairy herd improvement (DHI) composite-level SCC] for monitoring the herd DP IMI incidence and elimination rates. A cohort of 91 Canadian dairy herds was followed from 2007 to 2008. In each herd, a sample of 15 cows was selected each year, and a series of 2 predry and 2 postcalving quarter milk samples were collected. Routine milk bacteriological culture was conducted to identify IMI, SCC was measured on the quarter milk samples, and composite SCC of the last predry and first postcalving DHI tests were obtained. Mastitis pathogens were grouped into 3 categories: major pathogens, minor pathogens, and any pathogens. For each herd, DP bacteriological culture-derived IMI incidence and elimination rates were computed using quarter milk culture data. Similarly, SCC-derived herd incidence and elimination rates were computed using quarter and DHI composite-level SCC measurements and using various SCC thresholds to define new and eliminated IMI. Linear regression was used to compare herd quarter-level and compositelevel SCC-derived herd incidence and elimination with DP bacteriological culture-derived IMI incidence and elimination. Herd DP incidences computed by using quarter-level SCC, and with most of the SCC thresholds tested, were significant predictors of the DP major, minor, and any IMI incidences $(F$-test; $P \leq 0.05)$. The highest coefficients of determination $\left(\mathrm{R}^{2}\right)$ were obtained with thresholds of 200,000 ( $\left.\mathrm{R}^{2}: 12 \%\right)$ and 50,000 cells/ $\mathrm{mL}\left(\mathrm{R}^{2}: 25 \%\right)$ for predicting major and minor IMI, respectively. When using composite DHI SCC measurements, however, substantial losses of predictive power were seen for minor and any IMI incidences compared

Received June 15, 2012.

Accepted August 26, 2012.

${ }^{1}$ Corresponding author: simon.dufour@umontreal.ca with quarter-level SCC. For DP major IMI incidence, composite SCC yielded similar, but modest, predictive power when a cutoff value of 150,000 cells $/ \mathrm{mL}$ was chosen to define new IMI. To predict DP elimination rates, the value of quarter-level SCC seemed limited to predicting the DP major IMI elimination rate. Composite SCC, on the other hand, showed modest predictive power for major and minor IMI elimination rates, with thresholds of 200,000 and 50,000 cells/mL, respectively. Results from the current study suggest that quarter and composite SCC-derived rates could be used as substitutes for bacteriological culture-derived rates for some groups of mastitis pathogens.

Key words: dry period, intramammary infection, incidence, somatic cell count

\section{INTRODUCTION}

The dry period (DP) is recognized as a period of tremendous importance for the acquisition and elimination of IMI (Todhunter et al., 1991; Bradley and Green, 2000; Green et al., 2002). During the DP, the probability of a cow acquiring an IMI by environmental pathogens, such as enterobacterial organisms, is higher than during the lactating period, and this probability is particularly high at the very beginning and toward the end of the DP (Smith et al., 1985; Bradley and Green, 2004). Furthermore, IMI acquired during the DP will often be associated with flare-up of clinical mastitis in the following lactation (Green et al., 2002). The probability of eliminating an existing IMI during the DP is also higher than during the lactation (Halasa et al., 2009). For instance, cumulative elimination rates of subclinical Staphylococcus aureus IMI of $66 \%$ at dryingoff and of $34 \%$ during the lactation have been reported after treatment (Sol et al., 1994, 1997). Preventing the acquisition of new IMI (NIMI) during the DP and maximizing the elimination of existing IMI (EIMI) should therefore be 2 essential components of any mastitis control program, and the herd DP incidence and elimination rates should, consequently, be monitored on a regular basis. 
Although repeated bacteriological milk cultures have been used in the literature to measure the incidence and elimination of IMI, routine milk culture of every quarter or cow at drying-off followed by another milk culture after calving are often considered too costly for most dairy producers. Somatic cell count data, however, have been proposed as a proxy for IMI, and individual composite SCC are already measured monthly by DHI organizations on $75 \%$ of Canadian dairy herds (Canadian Dairy Information Centre, 2012) and are also widely available in most industrialized countries. Furthermore, some novel milking systems can now measure quarter SCC at milking, and these measurements could potentially be used to compute DP herd incidence and elimination rates by using predry and postcalving quarter-level SCC data.

Observing a composite SCC increase from fewer than to more than 200,000 cells/mL of milk has been suggested as an optimal threshold for predicting NIMI in lactating dairy cows (Dohoo and Leslie, 1991). Although thresholds for predicting EIMI or NIMI over the DP have not been formally evaluated, the same 200,000 cells $/ \mathrm{mL}$ threshold is often used to define EIMI and incident IMI over the DP (Cook et al., 2002; Schukken et al., 2003; Pantoja et al., 2009). Furthermore, the cumulative incidence and elimination rates of herd DP IMI derived from monthly individual cow SCC measurements are now reported by many DHI organizations. These measures are routinely monitored to evaluate herd performance and are often used to inform adjustments of the DP management strategies. The concept of cumulative incidence and elimination rates (i.e., the probability that a cow will acquire or eliminate an IMI over the DP) can be understood relatively easily by most dairy producers, practitioners, and extension agents, but it is a simplification of the problem. With the cumulative incidence or elimination rate, the risk of acquiring or eliminating an IMI is assumed to be independent of the DP length. This is equivalent to saying, for instance, that a cow that has been dried off for 1 mo would have the same risk of acquiring or eliminating an IMI as a cow that has been dried off for 3 mo. Because most NIMI and EIMI usually occur in relatively narrow periods of time (the first 2 wk after dry-off and the last 2 wk before calving), this assumption is, in most instances, a reasonable compromise (Smith et al., 1985; Bradley and Green, 2004). Nevertheless, with the DHI data that are usually available, incidence density and elimination density (i.e., the number of NIMI or EIMI per quarter-month or cow-month at risk) could be computed and would be more accurate and meaningful measures of the DP infection dynamic. Finally, regardless of the type of incidence and elimination rates that can be computed, no formal attempt has been made so far to evaluate the suitability of our surrogate measurements (i.e., the DP incidence and elimination rates of the herd derived from SCC measurements) as estimates of the more precise herd incidence and elimination rates that can be computed by using repeated bacteriological milk cultures.

The objective of the current study was therefore to evaluate the predictive ability of the herd DP IMI incidence and elimination rates (incidence and elimination density) derived from SCC measurements (quarterlevel SCC and monthly DHI composite SCC) by using various SCC thresholds to define NIMI and EIMI as estimates of the more precise herd DP IMI incidence and elimination rates (incidence and elimination density) that could be obtained by using repeated bacteriological quarter milk cultures.

\section{MATERIALS AND METHODS}

A cohort of 91 Canadian dairy herds, the National Cohort of Dairy Farms (NCDF) of the Canadian Bovine Mastitis Research Network (CBMRN), was constituted in 2006 and followed for 2 yr in 2007 and 2008. The herd selection process and the general characteristics of these herds have been described by Reyher et al. (2011). Briefly, herds were recruited in 4 areas of Canada based on the willingness of the dairy producer to participate in a 2-yr cohort study. Herds were selected to achieve a uniform distribution among 3 strata of bulk tank SCC and to reflect regional proportions of freestall housing systems.

In 2007, the first 15 cows to be dried off and that were expected to remain in the herd for at least $2 \mathrm{wk}$ after calving were recruited. A similar selection of cows was made early in 2008. Quarter milk samples were collected on the selected cows mainly by farm personnel, but also by CBMRN technicians between 4 and 2 wk before dry-off, between 2 wk and dry-off, within $24 \mathrm{~h}$ of calving, and from 1 to 2 wk after calving. Milk samples were frozen for storage and later thawed and cultured using a standardized protocol based on the National Mastitis Council (Verona, WI) guidelines for culture and species identification (Hogan et al., 1999). Briefly, $10 \mu \mathrm{L}$ of milk was streaked on a Columbia agar $+5 \%$ sheep blood plate and incubated aerobically at $35^{\circ} \mathrm{C}$ for up to $48 \mathrm{~h}$. The phenotypically different types of colonies were enumerated and speciated, using recommended bacteriological procedures (Hogan et al., 1999). The SCC of the quarter milk samples was then measured using a Fossomatic cell counter (Fossomatic 4000 series; Foss Electric A/S, Hillerød, Denmark). The composite SCC of the last predry and the first postcalving DHI tests was extracted from the DHI records of each selected cow. Somatic cell count measurements 
were therefore available at the quarter (CBMRN data) and composite level (DHI data).

\section{Definitions for Bacteriological Culture IMI, NIMI, EIMI, Incidence, and Elimination Rates}

IMI. Unless Staph. aureus or Streptococcus agalactiae were identified, milk samples with $>2$ phenotypically different species $(\mathrm{n}=6,897)$ were considered contaminated and were omitted from subsequent analyses (for details, see Reyher et al., 2011). Organisms were regrouped into 3 categories: major pathogens, minor pathogens, and any pathogens. Milk samples were considered positive for major pathogens whenever Staph. aureus, Strep. agalactiae, Streptococcus dysgalactiae, Streptococcus uberis, Escherichia coli, or Klebsiella spp. were retrieved in concentrations $\geq 100 \mathrm{cfu} / \mathrm{mL}$ of milk. Milk samples were considered positive for minor pathogens whenever CNS or Corynebacterium spp. were retrieved in concentrations of $\geq 200$ or $\geq 100 \mathrm{cfu} / \mathrm{mL}$ of milk, respectively. Finally, milk samples were considered positive for any pathogens whenever CNS were retrieved in concentrations of $\geq 200 \mathrm{cfu} / \mathrm{mL}$ of milk or when any other staphylococci, streptococci, or gramnegative species, or Corynebacterium spp., enterococci, Arcanobacterium pyogenes, Nocardia spp., Prototheca spp., yeast, or fungi were retrieved in concentrations of $\geq 100 \mathrm{cfu} / \mathrm{mL}$ of milk. These definitions were based on the recommendations of Dohoo et al. (2011b). To define quarter IMI status at drying-off, the 2 predry milk samples were interpreted in parallel (i.e., an IMI by a specific group of organisms was deemed to be present whenever $\geq 1$ milk sample was positive for this group of organisms). Intramammary infection status at calving was similarly defined using parallel interpretations.

NIMI. To define NIMI over the DP, the IMI status at drying off and that at calving were jointly considered. For each group of organisms, only quarters that were free of these organisms at drying off were considered at risk of acquiring a NIMI over the DP. A NIMI was deemed to have occurred whenever a quarter was found positive for these organisms at calving. Whenever a NIMI was observed, it was deemed to have occurred halfway between the last available predry and the last available postcalving samples.

EIMI. Statuses at drying off and at calving were similarly considered to define EIMI. For each group of organisms, only quarters that were positive for these organisms at dry-off were considered at risk of eliminating an IMI over the DP, and elimination of an IMI was deemed to have occurred whenever a quarter was found to be free of these organisms at calving. Whenever an EIMI was observed, it was deemed to have occurred halfway between the first available predry and the first available postcalving samples.

Incidence Rate. Quarter-level bacteriological culture DP herd incidences (BCI) were computed for each herd as follows: in each herd, the total number of quarters experiencing a NIMI over the DP was computed and divided by the total number of quarter-days at risk of NIMI acquisition; this rate was then multiplied by 30.5 to report quarter BCI in NIMI per quarter-month.

Elimination Rate. Quarter-level bacteriological culture DP herd elimination rates (BCE) were computed for each herd as follows: in each herd, the total number of quarters experiencing an EIMI over the DP was computed and divided by the total number of quarter-days at risk of IMI elimination; this rate was then multiplied by 30.5 to report quarter BCE in EIMI per quarter-month.

\section{Definitions for SCC-Derived NIMI, EIMI, Incidence, and Elimination Rates}

To define quarter-level NIMI and EIMI, quarter SCC measurements of the last available predry and of the last available postcalving samples were considered. The last available postcalving sample was always preferred over the sample collected within $24 \mathrm{~h}$ of calving to avoid bias attributable to the higher SCC usually found during the first 3 milkings after calving (Barkema et al., 1999). For composite-level analyses, SCC measurements of the cow's last predry and first postcalving DHI tests were used.

NIMI. The 200,000 cells/mL threshold proposed by Dohoo and Leslie (1991) for NIMI of lactating dairy cows was first used to define DP NIMI. Only quarters or cows with predry SCC $<200,000$ cells/mL were considered at risk of acquiring a NIMI, and a NIMI was deemed to have occurred whenever the postcalving SCC measurement was $\geq 200,000$ cells $/ \mathrm{mL}$. Whenever a NIMI was observed, it was deemed to have occurred halfway between the 2 SCC measurements.

EIMI. The same threshold was then used to define EIMI. For EIMI, only quarters or cows with predry SCC of $\geq 200,000$ cells $/ \mathrm{mL}$ were considered at risk of eliminating an IMI, and an IMI was deemed to have been eliminated whenever a postcalving SCC $<200,000$ cells/mL was observed. Whenever an EIMI was observed, it was deemed to have occurred halfway between the 2 SCC measurements.

Incidence and Elimination Rates. Quarter- and composite-level herd SCC-derived incidence (SCCI) and elimination rates (SCCE) were computed as was done for bacteriological culture-derived rates. Briefly, in each herd, the total number of quarters or cows (for 
composite-level analyses) experiencing a NIMI and the total number experiencing an EIMI over the DP were computed and divided, respectively, by the total numbers of quarter-days or cow-days (for compositelevel analyses) at risk of NIMI acquisition and of EIMI elimination. Again, these rates were multiplied by 30.5 to report rates in events/unit-month.

\section{Analyses}

Descriptive statistics were computed and the distribution was inspected for herd-level indices: quarterand composite-derived SCCI and SCCE, and herd BCI and $\mathrm{BCE}$ rates of major pathogens, minor pathogens, and any pathogens. The SCCI and SCCE rates were then compared with bacteriological culture-derived rates. It is important to acknowledge that bacteriological culture is not a gold-standard diagnostic test for IMI. Consequently, the computed herd BCI and BCE rates are not perfectly valid representations of the true herd IMI incidence and elimination rates. However, bacteriological culture would, in most instances, be the only other practical option that could be considered for long-term monitoring of the DP IMI dynamic in a large sample of herds. Therefore, the relationships between herd SCCI and BCI and between SCCE and BCE were explored. First, the shape of each relationship was explored by visual inspection of a locally weighted scatterplot smoothing curve (lowess). Each relationship was then modeled using simple linear regression. Whenever visual inspection of the lowess curve yielded doubts regarding the linearity of the relationship under investigation, quadratic or cubic SCCI terms, or both, were added to the model, tested for significance ( $F$-test, $\alpha \leq 0.05)$, and retained when appropriate.

To evaluate whether the level of subclinical mastitis in a herd had an effect on the relationships between SCC- and bacteriological culture-derived rates, the herd mean SCS during the 2-yr study period, computed from monthly DHI measurements, was then investigated as a potential effect modifier. To achieve this, the herd mean SCS and its interaction term with the SCC-derived rate under investigation were added to the model, and the interaction term was tested for significance ( $F$-test). To adjust for the numerous comparisons made, $\alpha \leq$ 0.01 was used to determine the significance of SCS as an effect modifier. The interaction term was never statistically significant; therefore, the associations under investigation were deemed to be constant across herd subclinical mastitis levels and are not discussed further in the remainder of the manuscript.

For all models, assumptions of normality and homogeneity of variance were evaluated by visual inspection of normal probability plots of residuals and of plots of residuals against predicted values, respectively. Leverage values were inspected to identify influential observations. Finally, limits of agreement plots (plots of the difference between pairs of data against their mean) between observed and predicted rates were sketched whenever a significant SCCI-BCI association was observed, and these were inspected to further explore the predictive ability of SCC-derived rates (Dohoo et al., 2009).

Finally, although the 200,000 cells/mL threshold proposed by Dohoo and Leslie (1991) was found to be optimal to diagnose NIMI when using a composite sample of lactating dairy cows, it is likely that one or many different thresholds may have been better choices for the population studied. Results from Sargeant et al. (2001), for instance, highlighted the benefits of using lower SCC thresholds to define prevalent IMI in early lactation (i.e., on d 5 postcalving). To investigate the effect of the SCC threshold value used to compute the incidence and elimination rate estimates, all analyses described were also conducted using alternative SCC thresholds of 50,000, 100,000, 150,000, and 250,000 cells $/ \mathrm{mL}$ to define NIMI and EIMI, and the predictive value of these different thresholds was compared.

\section{RESULTS}

A complete description of the NCDF herds is available elsewhere (Reyher et al., 2011). Briefly, the herds studied were milking, on average, 85 cows, had a mean 305 -d milk production of $9,781 \mathrm{~kg}$, and had a mean SCS of 2.7. Over the course of the study, a total of 10,083 quarter series were analyzed and, on average, 111 (SD: 34) quarter series were available per herd to estimate bacteriological culture-derived incidence and elimination rates. These series were obtained from 2,528 cows. The mean DP duration was 81 d (SD: 24; range: 12 , 264). Universal dry cow therapy (i.e., antibiotic administered to all quarters of all cows) was used on $88 \%$ of the NCDF herds during the study period (Dufour et al., 2010). The 2 DHI tests used to estimate cow-level SCCI and SCCE were conducted, on average, $18 \mathrm{~d}$ (SD: 14) before drying off and at $19 \mathrm{~d}$ (SD: 12; range: 7 to $64 \mathrm{~d})$ after calving.

A description of the NCDF bacteriological culturederived incidence and elimination rates is available elsewhere [D. Haines (Université de Montréal, St-Hyacinthe, QC, Canada), A. M. Elmoslemany (University of Prince Edward Island, Charlottetown, PE, Canada), H. Stryhn (University of Prince Edward Island), H. W. Barkema (University of Calgary, Calgary, AB, Canada), G. Keefe (University of Prince Edward Island), K. Leslie (University of Guelph, Guelph, ON, Canada), D. Kelton (University of Guelph), D. T. Scholl (South 
Dakota State University, Brookings), and I. R. Dohoo, unpublished data]. Briefly, the herd quarter-level major, minor, and any IMI BCI distributions were all right skewed, with medians $(25 \mathrm{th}, 75 \mathrm{th}$ percentile) of 0.02 $(0.00,0.03), 0.14(0.09 .0 .23)$, and $0.21(0.13,0.29)$ NIMI/quarter-month, respectively. The herd quarterand composite-level SCCI distributions were right skewed as well, with medians (25th, 75th percentile) of $0.07(0.04,0.11) \mathrm{NIMI} /$ quarter-month and 0.05 (0.02, $0.08)$ NIMI/cow-month, respectively.

The herd quarter-level major, minor, and any IMI BCE all followed relatively normal distributions, with medians (25th, 75th percentile) of $0.50(0.29,0.77), 0.35$ (0.28. 0.45), and $0.25(0.18,0.34)$ EIMI/quarter-month, respectively. The herd quarter- and composite-level SCCE also followed normal distributions, with medians (25th, 75th percentile) of $0.54(0.45,0.66)$ EIMI/ quarter-month and $0.29(0.19,0.38)$ EIMI/cow-month, respectively.

\section{IMI Incidence}

Quarter-Level SCC. Relationships between quarter-level SCCI, computed using the 200,000 cells/ $\mathrm{mL}$ threshold, and major, minor, and any IMI BCI are illustrated in Figure 1. For all groups of organisms, a linear and positive relationship was observed between SCCI and BCI. Estimates of associations between quarter-level SCCI $(200,000$ cells/mL threshold) and BCI are reported in Table 1. Quarter-level SCCI was a significant predictor of the major, minor, and any IMI BCI and could explain a relatively large proportion of the variance in BCI (Table 1). For the 3 groups of organisms, the limits of agreement plots showed a noticeable trend, with the difference between observed and predicted BCI gradually increasing as the mean incidence increased (Figure 2). Furthermore, an increasing variation in the level of disagreement between SCCI and BCI measurements with an increasing mean incidence value could be seen for the 3 groups of organisms. In most instances, the larger absolute disagreements were observed in herds with a relatively high observed IMI incidence. These herds BCI were generally underestimated by using SCCI. Such herds, however, represented $<10 \%$ of the herds studied.

Composite DHI SCC. Relationships between composite-level SCCI, computed using the 200,000 cells/mL threshold, and major, minor, and any IMI BCI are presented in Figure 1. Again, for all groups of organisms, a relatively linear and positive relationship between SCCderived IMI incidence and BCI was observed. Estimates of associations between composite-level SCCI $(200,000$ cells/mL threshold) and major, minor, and any IMI BCI are presented in Table 1. Estimates of associations between composite SCCI and BCI were fairly similar to their quarter-level counterparts (Table 1). Composite SCCI, however, was not a significant predictor of major or minor IMI BCI and could explain $<5 \%$ of these variances in BCI. At the composite level, SCCI was still a significant predictor of any IMI BCI and would have explained $7 \%$ of its variability. For this latter group of organisms, increasing differences between observed and predicted BCI could be seen with an increasing mean incidence (Figure 2). Larger absolute disagreements were observed in the few herds with any observed IMI $\mathrm{BCI}>0.4 \mathrm{NIMI} /$ quarter-month.

\section{IMI Elimination}

Quarter-Level SCC. Relationships between quarter-level SCCE, computed using the 200,000 cells/mL threshold, and major, minor, and any IMI BCE are illustrated in Figure 3. A linear and positive relationship between major IMI BCE and SCCE was observed. Minor and any IMI BCE, on the other hand, were relatively constant across SCCE values. Estimates of association between SCCE (200,000 cells/mL threshold) and major, minor, and any IMI BCE are presented in Table 2. Quarter-level SCCE was not a significant predictor of the minor or any IMI BCE. The SCCE was, however, a significant predictor of major IMI BCE and could explain $10 \%$ of the major IMI elimination rate variance. Limits of agreement plots between observed and predicted elimination rates are presented in Figure 4. Again, increasing differences between observed and predicted BCE could be seen with an increasing mean elimination rate. The variability in these differences was, however, relatively constant across mean elimination rate values.

Composite DHI SCC. Relationships between the 200,000 cells/mL threshold composite-level SCCE and major, minor, and any IMI BCE can be found in Figure 3 . These relationships were fairly similar to their respective quarter-level counterparts. Estimates of association between composite-level SCCE $(200,000$ cells/mL threshold) and the different groups of organism BCE are presented in Table 2. Composite-level SCCE was not a significant predictor of any IMI BCE. Compositelevel SCCE was, however, a significant predictor of major and minor IMI BCE, but would have explained 9 and only $6 \%$ of the variability in these BCE. As seen before, a trend toward increasing differences between observed and predicted $\mathrm{BCE}$ as the mean elimination rate increased could be seen for these 2 groups of organisms (Figure 4).

Alternative SCC Thresholds. The predictive power of SCC-derived DP IMI incidence and elimination rates when different alternative SCC thresholds 


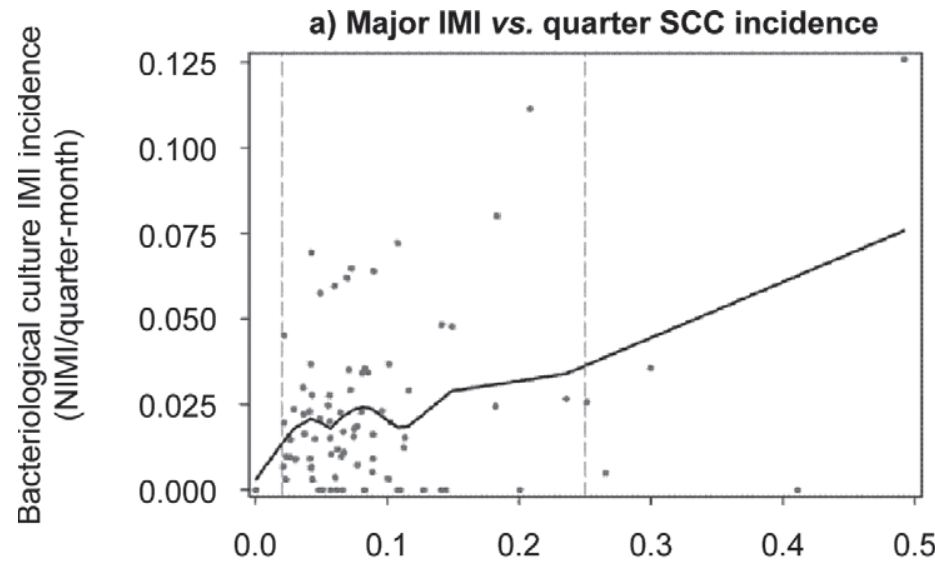

b) Major IMI vs. composite DHI SCC incidence

c) Minor IMI vs. quarter SCC incidence

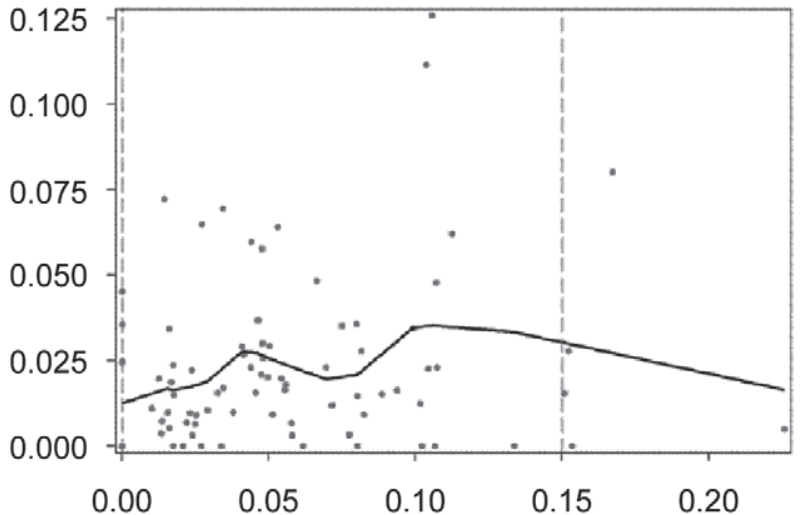

d) Any IMI vs. composite DHI SCC incidence
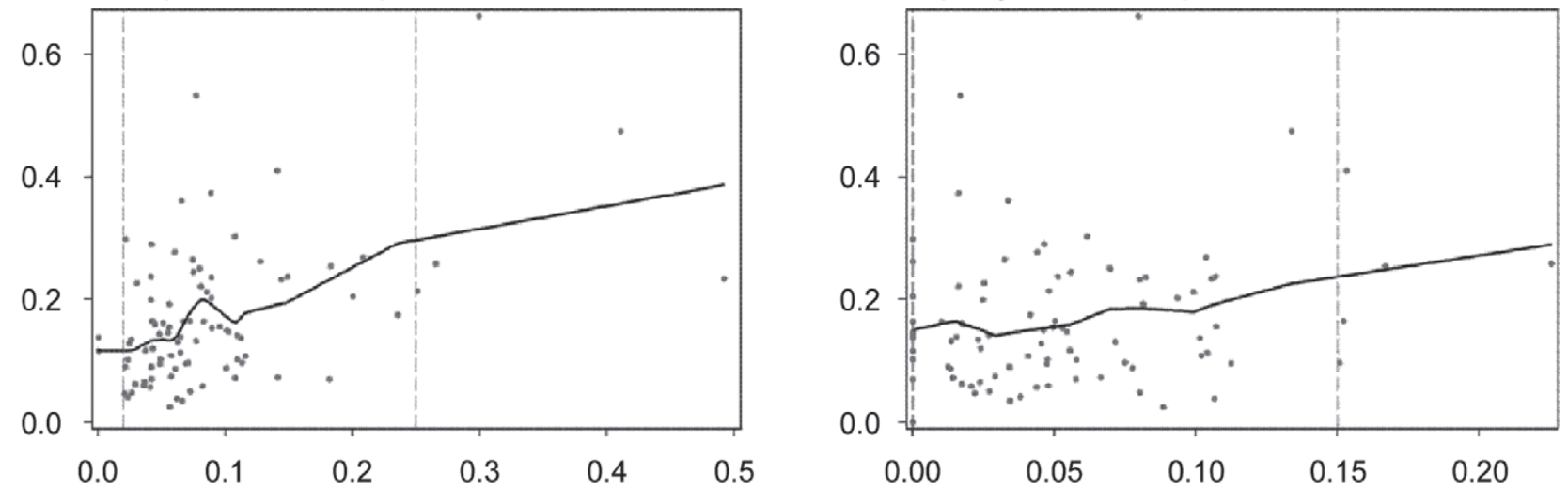

e) Any IMI vs. quarter SCC incidence
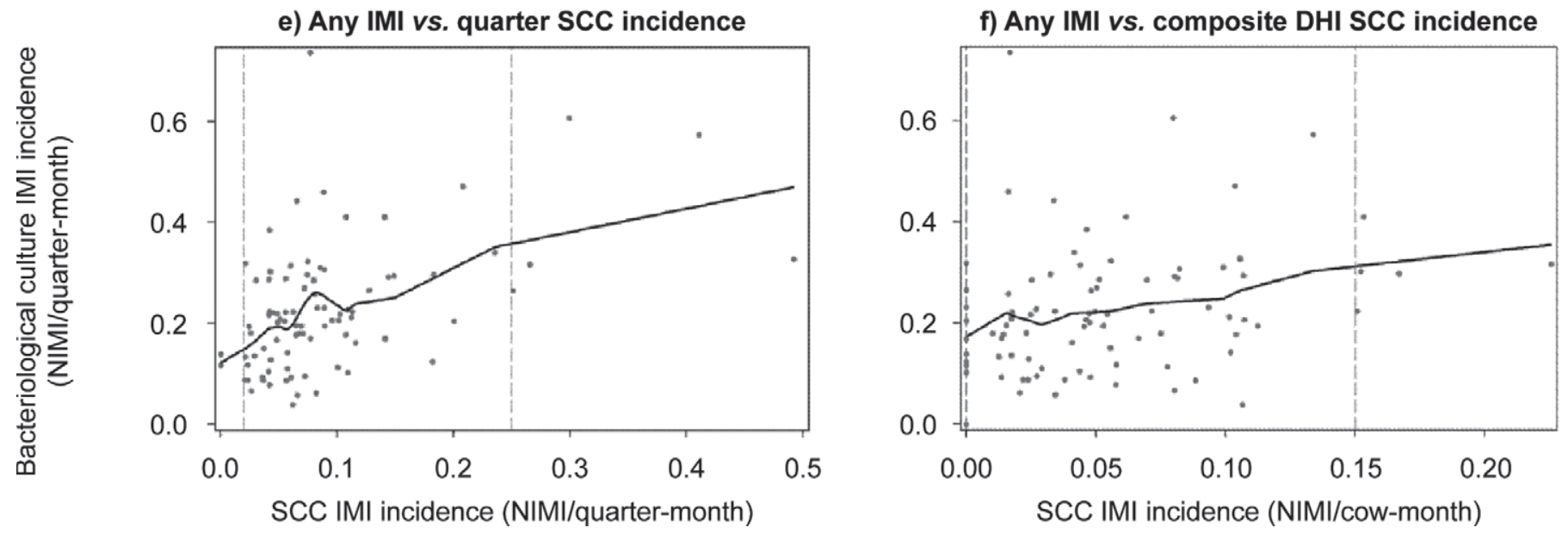

Figure 1. Scatter plots of SCC-derived herd IMI incidence (SCCI) versus bacteriological culture-derived herd IMI incidence (BCI) with a lowess smoothed curve for 3 groups of organisms and for quarter and DHI composite SCC measurements, using an SCC threshold of 200,000 cells/mL to define new IMI (NIMI). The SCCI 5th and 95th percentiles are represented by vertical dashed lines.

are used to define NIMI and EIMI are presented in Table 3. For quarter-SCC measurements, in most situations many or all of the proposed thresholds showed fairly similar coefficients of determination. For major IMI incidence, for instance, the 150,000, 200,000, and
250,000 cells/mL thresholds yielded similar modest predictive values (range: 9 to 12\%), with the 200,000 cells $/ \mathrm{mL}$ threshold model showing a slightly higher coefficient of determination. For minor and any IMI incidence, all the thresholds under investigation were 
Table 1. Results of 6 linear regression models on the relationship between SCC-derived herd IMI incidence (SCCI) and quarter milk bacteriological culture-derived herd IMI incidence (BCI) for 3 groups of organisms and for quarter- and composite-level SCC, using an SCC threshold of 200,000 cells/mL to define new IMI (NIMI)

\begin{tabular}{|c|c|c|c|c|}
\hline Dependent variable of the model & Fixed effect & Estimate & $95 \% \mathrm{CI}$ & $\mathrm{R}^{21}$ \\
\hline \multirow[t]{2}{*}{ Major IMI BCI } & Intercept & 0.013 & $0.006,0.021$ & \multirow[t]{2}{*}{0.12} \\
\hline & Quarter SCCI ${ }^{2}$ & 0.104 & $0.042,0.165^{*}$ & \\
\hline Minor IMI BCI & Quarter SCCI ${ }^{2}$ & 0.643 & $0.377,0.909^{*}$ & 0.22 \\
\hline \multirow[t]{2}{*}{ Any IMI BCI } & Intercept & 0.161 & $0.125,0.197$ & \multirow[t]{2}{*}{0.22} \\
\hline & Quarter SCCI ${ }^{2}$ & 0.730 & $0.434,1.025^{*}$ & \\
\hline \multicolumn{5}{|l|}{ Composite DHI SCC analysis } \\
\hline Major IMI BCI & Composite $\mathrm{SCCI}^{3}$ & 0.110 & $-0.005,0.225$ & 0.04 \\
\hline \multirow[t]{2}{*}{ Minor IMI BCI } & Intercept & 0.140 & $0.103,0.177$ & \multirow[t]{2}{*}{0.04} \\
\hline & Composite $\mathrm{SCCI}^{3}$ & 0.530 & $0.000,1.059$ & \\
\hline \multirow{2}{*}{ Any IMI BCI } & Intercept & 0.184 & $0.143,0.225$ & \multirow{2}{*}{0.07} \\
\hline & Composite $\mathrm{SCCI}^{3}$ & 0.764 & $0.178,1.349^{*}$ & \\
\hline
\end{tabular}

${ }^{1}$ Coefficient of determination of the model.

${ }^{2}$ The SCCI in NIMI/quarter-month for quarter-level analyses.

${ }^{3}$ The SCCI in NIMI/cow-month for composite-level analyses.

$* P \leq 0.05$; SCCI is a significant predictor of the quarter BCI under investigation.

able to explain a relatively large portion of the variance in herd incidence (range: 19 to $25 \%$ ). For both groups of organisms, using the 50,000 cells/mL threshold produced slightly higher coefficients of determination.

Conversely, when using composite SCC measurements to predict herd IMI incidence, relatively small predictive values were obtained regardless of the threshold used and the pathogen studied. The composite SCC-derived incidence computed using a threshold of 150,000 cells/ $\mathrm{mL}$ was a significant predictor of major IMI incidence and could explain 9\% of the herd variance in major IMI incidence. Although other composite SCC-derived incidence rates computed using different thresholds were sometimes found to be significant predictors of the minor and any IMI incidence, the proportion of variance in IMI incidence explained was relatively small (range: 4 to $7 \%$ ).

When trying to predict the herd DP IMI elimination rate, the value of quarter SCC measurements appeared to be limited to predicting the major IMI elimination rate. For this group of organisms, SCCI computed using thresholds ranging from 100 to 250,000 cells $/ \mathrm{mL}$ were able to explain 10 to $13 \%$ of the variance in the major IMI elimination rate. Composite SCC measurements could also be used to predict DP IMI incidences and were able to explain a relatively small proportion of the variance in the IMI elimination rate of major IMI (using a 200,000 cells/mL threshold), of minor IMI (using a 50,000 cells/mL threshold), and of any IMI (using a 250,000 cells/mL threshold).

Finally, limits of agreement plots between predicted and observed rates for the alternative SCC thresholds revealed very similar patterns of disagreement as those described for the 200,000 cells/mL threshold (data not shown). Briefly, for DP IMI incidence analyses, the largest absolute disagreements were observed in herds with a relatively high observed IMI incidence. The IMI incidences of these herds were generally underestimated by using SCC measurements. For DP IMI elimination analyses, increasing differences between the observed and predicted elimination rates could be seen with an increasing mean elimination rate. In all models, the assumptions of normality and homogeneity of the variances were reasonable.

\section{DISCUSSION}

This is the first study presenting a formal evaluation of the herd DP incidence and elimination rate estimates that can be derived from predry and postcalving quarter or DHI composite SCC data. In the current study, SCCderived herd incidence and elimination rates were compared with bacteriological culture-derived rates rather than with the true rates that could be computed using a hypothetical gold-standard test. Although incidence and elimination rates can be computed using a variety of diagnostic tests, bacteriological culture is often the only other practical option that will be considered for long-term frequent monitoring of the DP IMI dynamic in a large sample of herds. Most often, SCC-derived incidence and elimination rates would therefore be used as a substitute for bacteriological culture-derived rates. It is important to realize, however, that the bacteriological culture-derived incidence and elimination rates are themselves potentially inexact approximations of the true rates. First, the sensitivity and specificity of 

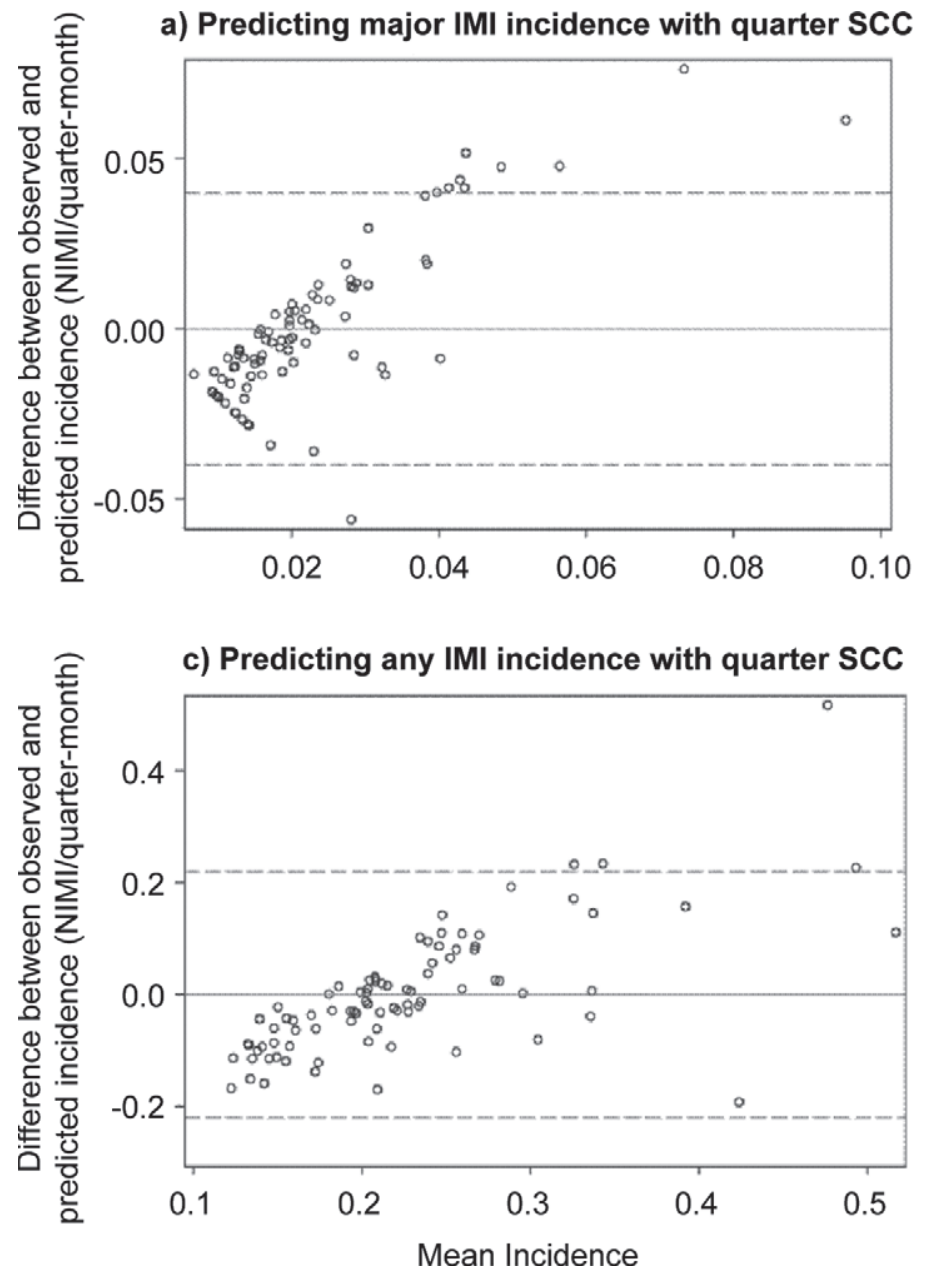

b) Predicting minor IMI incidence with quarter SCC

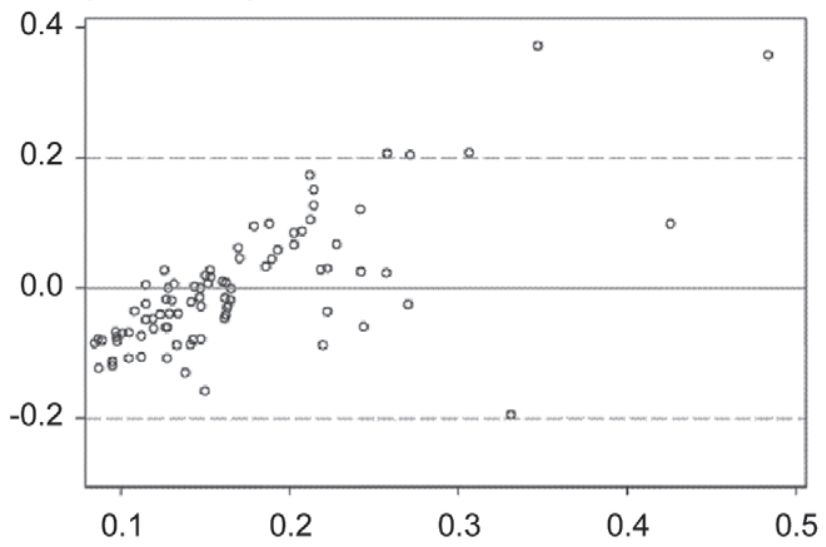

c) Predicting any IMI incidence with composite DHI SCC

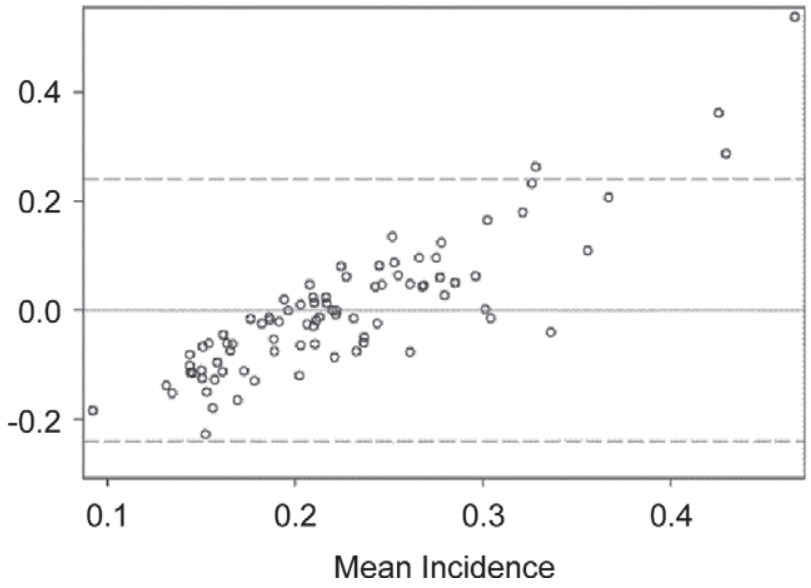

Figure 2. Limits of agreement plots between observed dry period IMI incidence and IMI incidence predictions using predry and postcalving SCC measurements for different groups of organisms for incidence predictions based on quarter and DHI composite SCC measurements, using an SCC threshold of 200,000 cells/mL to define new IMI (NIMI). The mean incidence difference is represented by the horizontal full line. Limits of agreement lines (mean difference $\pm 1.96 \mathrm{SD}$ ) are represented by horizontal dashed lines.

milk bacteriological culture have been shown to vary quite a lot from one pathogen to another and can be quite deceiving for some groups of pathogens, such as the CNS or the Enterococcus spp. (Dohoo et al., 2011b). The parallel interpretation of duplicate milk samples used in the current study, however, would actually yield a certain gain of sensitivity for many of the pathogens involved, but at the cost of a lower specificity (Dohoo et al., 2011a). A certain level of bias of the bacteriological culture incidence and elimination rate estimates is therefore expected.

Second, some quarters may have been wrongfully identified as having a persistent IMI over the DP because of the categorization of specific mastitis pathogens into broader categories. This would have happened whenever a quarter infected with a specific pathogen would have truly eliminated this pathogen over the DP but would have acquired, over the same period, another IMI from a pathogen belonging to the same group of organisms. In such situations, both an EIMI and a NIMI would have been missed. This problem, however, appeared to be quite limited for the major pathogens category, in which incident and eliminated IMI were less commonly seen. In the current study, only 2 DP Staph. aureus NIMI (of the 245 Staph. aureus recorded NIMI) were masked, for instance, by the presence of another major pathogen at dry-off. Similarly, only 8 DP Staph. aureus EIMI (of the 222 Staph. aureus recorded EIMI) were concealed by the presence of another major pathogen after calving. This problem, on the other hand, appeared to be substantial for the minor pathogens category and, consequently, for the any pathogens category. Approximately $20 \%$ of the observed Corynebacterium spp. NIMI and EIMI, for instance, were misdiagnosed as DP persistent minor pathogen IMI because of the presence of a CNS IMI at 


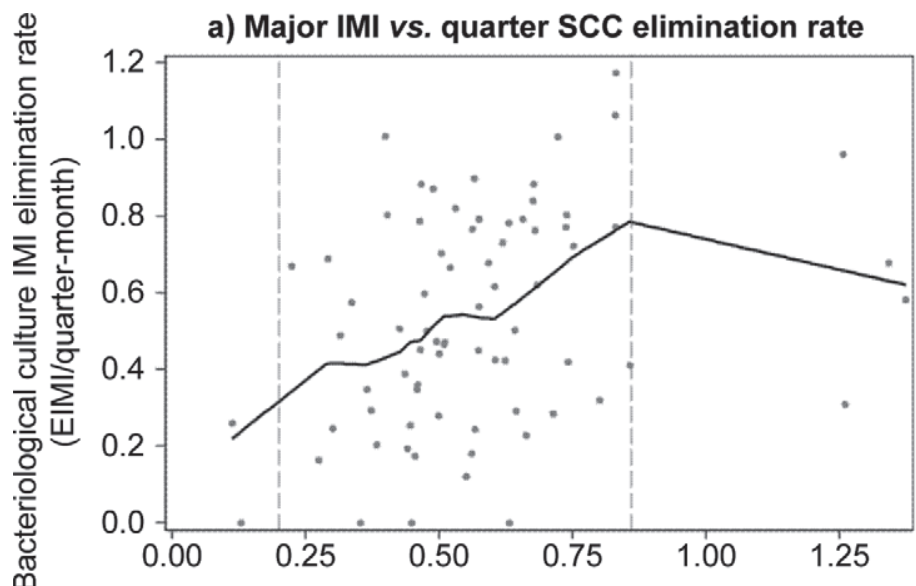

b) Major IMI vs. composite DHI SCC elimination rate
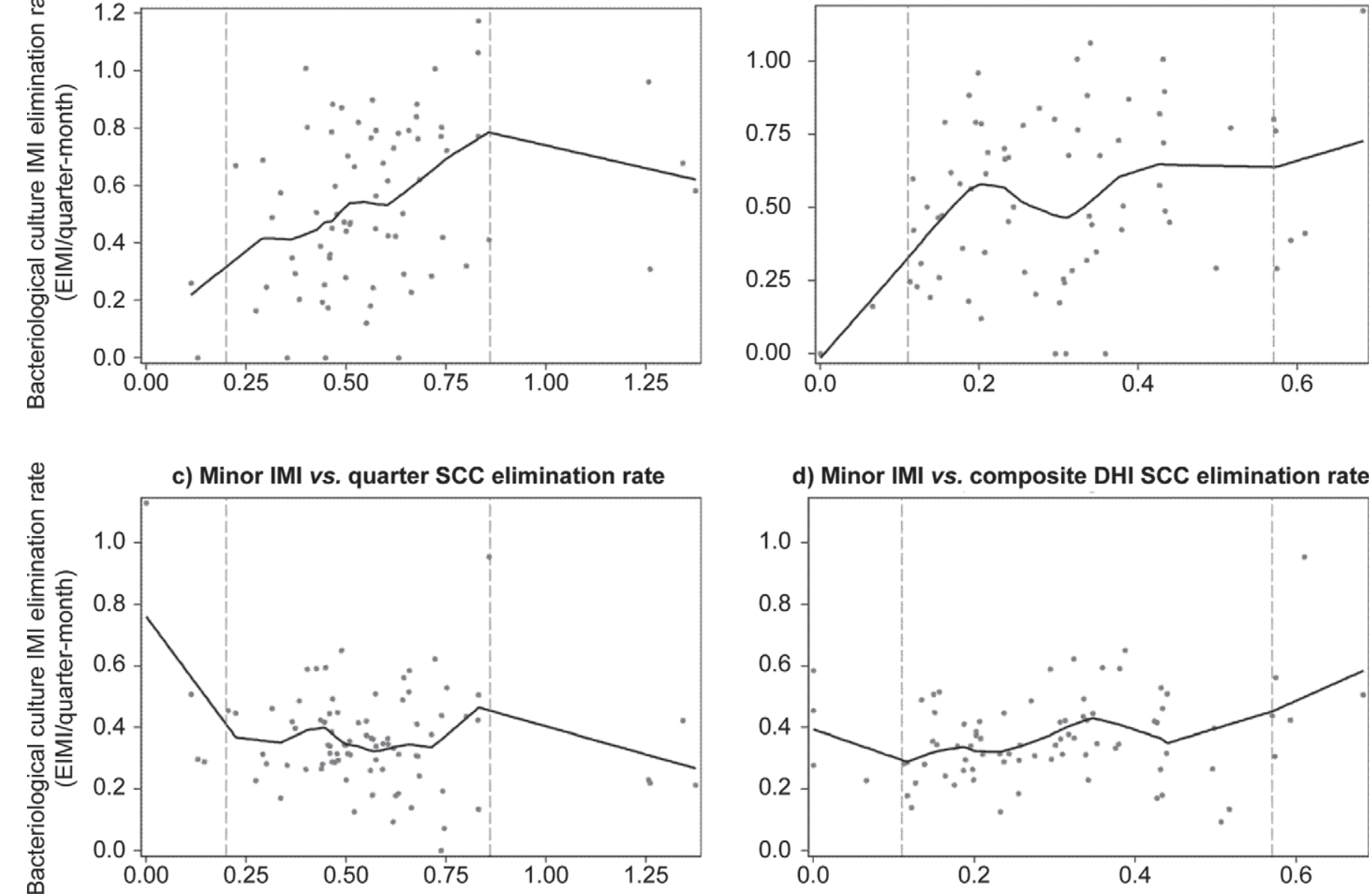

d) Minor IMI vs. composite DHI SCC elimination rate
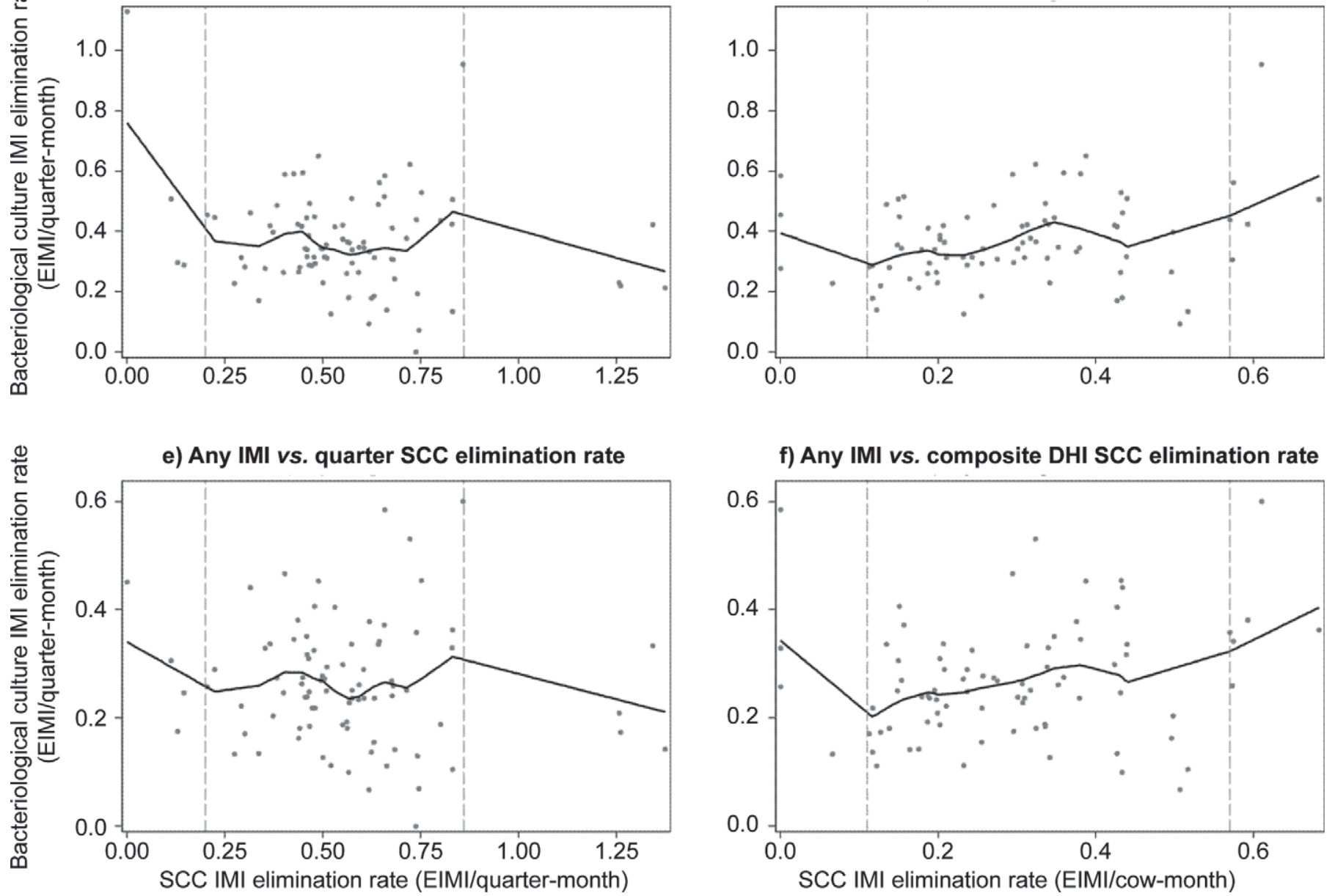

f) Any IMI vs. composite DHI SCC elimination rate

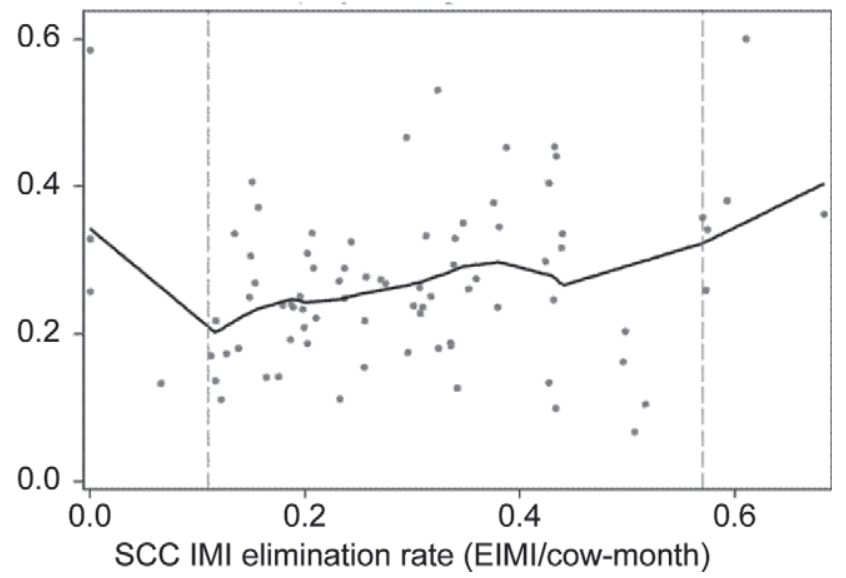

Figure 3. Scatter plots of SCC-derived herd IMI elimination rate (SCCE) versus bacteriological culture-derived herd IMI elimination rate (BCE) with a lowess smoothed curve for 3 groups of organisms and for quarter and DHI composite SCC measurements, using an SCC threshold of 200,000 cells/mL to define eliminated IMI (EIMI). The SCCE 5th and 95th percentiles are represented by vertical dashed lines.

dry-off or calving, respectively. Similarly, approximately 20 and $10 \%$ of CNS NIMI and EIMI, respectively, were misdiagnosed as persistent minor pathogen IMI because of the presence of a Corynebacterium spp. IMI. Actually, the relatively high rate of acquisition of new CNS IMI around calving time that has been reported 
Table 2. Results of 6 linear regression models on the relationship between SCC-derived herd IMI elimination rate (SCCE) and quarter milk bacteriological culture-derived herd IMI elimination rate (BCE) for 3 groups of organisms and for quarter- and composite-level SCC, using an SCC threshold of 200,000 cells/mL to define eliminated IMI (EIMI)

\begin{tabular}{|c|c|c|c|c|}
\hline Dependent variable of the model & Fixed effect & Estimate & $95 \% \mathrm{CI}$ & $\mathrm{R}^{21}$ \\
\hline \multirow[t]{2}{*}{ Major IMI BCE } & Intercept & 0.312 & $0.148,0.476$ & \multirow[t]{2}{*}{0.10} \\
\hline & Quarter $\mathrm{SCCE}^{2}$ & 0.379 & $0.116,0.641 *$ & \\
\hline Minor IMI BCE & Quarter $\mathrm{SCCE}^{2}$ & -0.137 & $-0.288,0.013$ & 0.04 \\
\hline \multirow[t]{2}{*}{ Any IMI BCE } & Intercept & 0.285 & $0.222,0.347$ & \multirow[t]{2}{*}{0.01} \\
\hline & Quarter $\mathrm{SCCE}^{2}$ & -0.037 & $-0.140,0.066$ & \\
\hline Major IMI BCE & Composite $\mathrm{SCCE}^{3}$ & 0.580 & $0.127,1.033^{*}$ & 0.09 \\
\hline \multirow[t]{2}{*}{ Minor IMI BCE } & Intercept & 0.301 & $0.234,0.369$ & \multirow[t]{2}{*}{0.06} \\
\hline & Composite $\mathrm{SCCE}^{3}$ & 0.228 & $0.023,0.433^{*}$ & \\
\hline \multirow{2}{*}{ Any IMI BCE } & Intercept & 0.231 & $0.178,0.283$ & \multirow{2}{*}{0.03} \\
\hline & Composite $\mathrm{SCCE}^{3}$ & 0.132 & $-0.028,0.292$ & \\
\hline
\end{tabular}

${ }^{1}$ Coefficient of determination of the model.

${ }^{2}$ The SCCE in EIMI/quarter-month for quarter-level analyses.

${ }^{3}$ The SCCE in EIMI/cow-month for composite-level analyses.

$* P \leq 0.05$; SCCE is a significant predictor of the quarter BCE under investigation.

in a recent study [D. Haines (Université de Montréal, St-Hyacinthe, QC, Canada), A. M. Elmoslemany (University of Prince Edward Island, Charlottetown, PE, Canada), H. Stryhn (University of Prince Edward Island), H. W. Barkema (University of Calgary, Calgary, AB, Canada), G. Keefe (University of Prince Edward Island), K. Leslie (University of Guelph, Guelph, ON, Canada), D. Kelton (University of Guelph), D. T. Scholl (South Dakota State University, Brookings), and I. R. Dohoo, unpublished data] has possibly resulted in a downward bias of the elimination rates whenever these IMI were considered and could explain the counterintuitive low median $\mathrm{BCE}$ for the minor and any IMI groups of organisms. Nevertheless, we could assume that SCC-derived incidence and elimination rates would be similarly affected by the presence of quarters infected both at dry-off and after calving but with different pathogens. The SCCI-BCI and SCCE-BCE relationships would therefore remain relatively unbiased.

Our results suggest that quarter SCC could be a very valuable substitute for milk bacteriological culture to help monitor the herd DP IMI incidence. In the current study, quarter-level SCCI was significantly associated with major, minor, and any IMI BCI and could explain a relatively important proportion of the variability of these BCI. Predry and postcalving quarter SCC measurements could therefore potentially be used to monitor the herd DP IMI incidence of these groups of pathogens. Although very few differences in predictive power of the different SCC thresholds tested were seen when using quarter-level SCC measurements, a threshold of 200,000 cells/mL to define NIMI appeared to yield the SCCI that most accurately predicted herd major IMI incidence. Whenever minor pathogens were considered, however, SCCI computed using a threshold of 50,000 cells $/ \mathrm{mL}$ to define NIMI appeared to yield SCCI values that were more closely associated with the herd IMI incidence. These results suggest that different thresholds should be used for monitoring the herd DP major and minor IMI incidences. It is important to keep in mind, however, that regardless of the chosen SCC threshold, the SCC-derived incidence rate carried an important level of imprecision for the small proportion of herds in which relatively high IMI incidences were observed. This surrogate could therefore lead to inappropriate conclusions in the small proportion of herds experiencing very high DP IMI incidence.

The value of using composite DHI SCC data as a substitute for bacteriological culture to monitor the herd DP IMI incidence, on the other hand, seemed to be more limited. Even with the wide range of SCCI definitions used in the current study, composite-level SCCI could explain only a small proportion of the herd DP major IMI incidence variability (using the 150,000 cells $/ \mathrm{mL}$ threshold). For the 3 groups of organisms under investigation, important reductions in the predictive power of the model were observed when composite DHI SCC-derived incidence rates were used instead of quarter-level SCC-derived rates. The loss of information resulting from pooling of the 4 quarter milk samples into a composite sample may have substantially affected the relationships between SCCI and BCI. A substantial loss of precision between quarter- and cow-level SCC has been reported when using online SCC to detect clinical mastitis (Mollenhorst et al., 2010). Furthermore, the time lag (roughly $18 \mathrm{~d}$ ) between DHI composite SCC 
a) Predicting major IMI elimination rate with quarter SCC

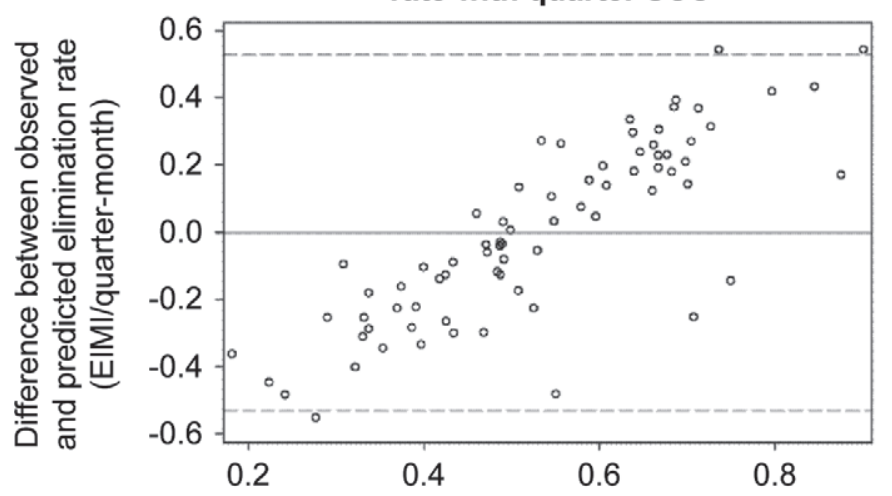

b) Predicting major IMI elimination rate with composite DHI SCC
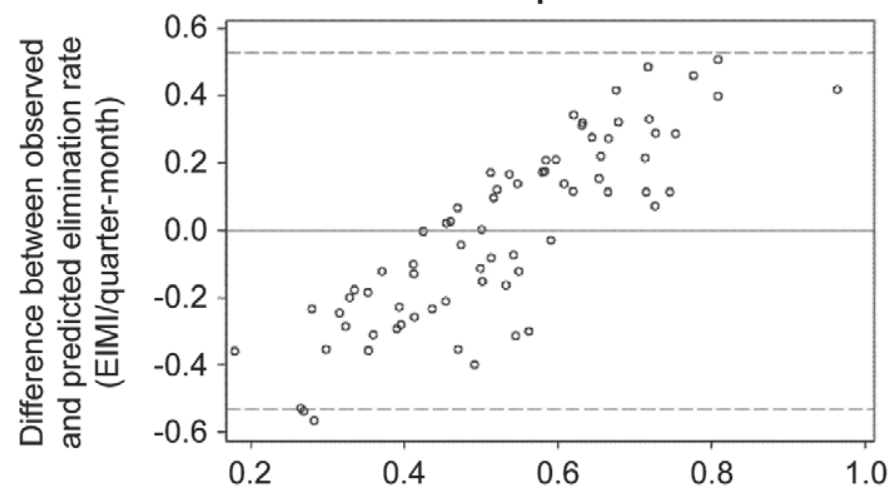

c) Predicting minor IMI elimination rate with composite DHI SCC

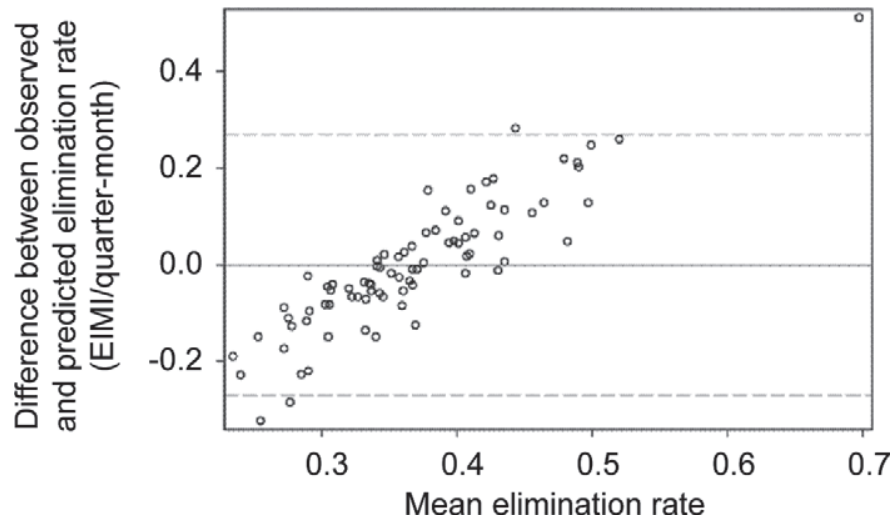

Figure 4. Limits of agreement plots between observed dry period IMI elimination rate and IMI elimination rate predictions using predry and postcalving SCC measurements for different groups of organisms, for elimination rate predictions based on quarter and DHI composite SCC measurements, using an SCC threshold of 200,000 cells $/ \mathrm{mL}$ to define eliminated IMI (EIMI). The mean elimination rate difference is represented by the horizontal full line. Limits of agreement lines (mean difference $\pm 1.96 \mathrm{SD}$ ) are represented by horizontal dashed lines. measurement and bacteriological milk culture could be responsible for the lack of association between cow-level SCCI and BCI. The additional undesired variability in the composite SCC, together with the time lag between SCC and bacteriological culture measurement, may have hampered the usefulness of composite SCCI as a substitute for BCI. Nevertheless, using predry and postcalving DHI composite SCC measurements to estimate the herd DP major IMI incidence seemed to be of some value when a 150,000 cells/mL threshold was used to define NIMI.

Results from the current study suggest that quarter and DHI composite SCC measurements could be appropriate substitutes for milk bacteriological culture for regular monitoring of the herd DP major IMI elimination rate. For quarter-level SCC measurements, SCC thresholds ranging from 150,000 to 250,000 cells $/ \mathrm{mL}$ would yield relatively modest predictive value. When using composite DHI SCC measurements, a threshold of 200,000 cells/mL appeared to be more closely associated with the herd DP major IMI elimination rate. However, using quarter-level SCC measurements to estimate minor or any pathogen elimination rates seemed to be of little value. This latter finding raises doubts regarding the validity of the results obtained with composite SCC, which showed a modest predictive value of the SCC-derived elimination rate computed using a 50,000 cells $/ \mathrm{mL}$ threshold as a predictor of the herd DP minor IMI elimination rate.

Finally, it is important to remember that the results reported in the current study, in terms of predictive value of the different SCC thresholds, strictly apply to prediction of the herd IMI incidence and elimination rates. Thresholds yielding the highest predictive value possibly did so because of an optimal balance between correctly classified NIMI or EIMI (i.e., the numerator of the rate) and of correctly classified individuals at risk (i.e., the denominator of the rate). These thresholds are likely to yield very different predictive values when used to predict the occurrence of NIMI or EIMI at the cow or quarter level. Results of the current study should therefore not be used for this latter purpose.

\section{CONCLUSIONS}

Results from the current study confirm that quarter SCC data, which can now be routinely measured by novel milking systems, could be extremely useful to estimate the rate of acquisition of IMI between dry-off and calving. For this purpose, SCC-derived incidence rates computed using NIMI definitions based on SCC thresholds of 200,000 and 50,000 cells $/ \mathrm{mL}$ would be recommended for monitoring of major and minor patho- 
Table 3. Predictive power of SCC-derived dry period IMI incidence and elimination rates when compared with bacteriological culture-derived rates, computed using a range of different SCC thresholds to define new IMI and eliminated IMI

\begin{tabular}{|c|c|c|c|c|}
\hline \multirow[b]{2}{*}{ SCC analysis level } & \multirow[b]{2}{*}{ Group of bacteria } & \multirow[b]{2}{*}{ SCC threshold ${ }^{1}$ (cells/mL) } & \multicolumn{2}{|c|}{$\mathrm{R}^{22}$} \\
\hline & & & IMI incidence & IMI elimination \\
\hline \multirow{11}{*}{ Quarter } & \multirow{4}{*}{ Major IMI } & 100,000 & 0.01 & $0.10^{*}$ \\
\hline & & 150,000 & $0.09^{*}$ & $0.13^{*}$ \\
\hline & & 200,000 & $0.12^{*}$ & $0.10^{*}$ \\
\hline & & 250,000 & $0.11^{*}$ & $0.13^{*}$ \\
\hline & \multirow{3}{*}{ Minor IMI } & 150,000 & $0.22 *$ & 0.03 \\
\hline & & 200,000 & $0.22^{*}$ & 0.04 \\
\hline & & 250,000 & $0.19^{*}$ & 0.02 \\
\hline & \multirow[t]{4}{*}{ Any IMI } & 50,000 & $0.23^{*}$ & 0.01 \\
\hline & & 100,000 & $0.19^{*}$ & 0.00 \\
\hline & & 150,000 & $0.22^{*}$ & 0.04 \\
\hline & & 200,000 & $0.22^{*}$ & 0.01 \\
\hline \multirow{11}{*}{ Composite } & Major IMI & 250,000 & 0.03 & 0.04 \\
\hline & \multirow[t]{5}{*}{ Minor IMI } & 50,000 & $0.05^{*}$ & $0.10^{*}$ \\
\hline & & 100,000 & 0.00 & 0.03 \\
\hline & & 150,000 & 0.00 & 0.02 \\
\hline & & 200,000 & 0.04 & $0.06^{*}$ \\
\hline & & 250,000 & $0.04^{*}$ & $0.06^{*}$ \\
\hline & \multirow[t]{5}{*}{ Any IMI } & 50,000 & 0.04 & 0.04 \\
\hline & & 100,000 & 0.00 & 0.03 \\
\hline & & 150,000 & 0.01 & 0.01 \\
\hline & & 200,000 & $0.07^{*}$ & 0.03 \\
\hline & & 250,000 & $0.07^{*}$ & $0.06^{*}$ \\
\hline
\end{tabular}

${ }^{1}$ Somatic cell count threshold used to define new IMI and eliminated IMI.

${ }^{2}$ Coefficient of determination of the model.

$* P \leq 0.05$; SCC-derived rate is a significant predictor ( $F$-test) of the bacteriological culture-derived rate under investigation.

gen IMI incidences, respectively. Furthermore, DHI composite SCC used with a 150,000 cells/mL threshold to define NIMI showed some potential for monitoring the acquisition rate of major IMI. Finally, DHI composite SCC and quarter SCC data could potentially be used as substitutes for milk bacteriological culture to estimate and monitor the herd major IMI elimination rate over the DP. Further research would be needed to confirm whether fluctuations of the SCC-derived DP incidence and elimination rates could actually be used to inform modification of the DP management strategies and to better understand the relevance of a given variation of these rates.

\section{ACKNOWLEDGMENTS}

The authors thank all the dairy producers, animal health technicians, and CBMRN regional coordinators (Herman Barkema, University of Calgary, Calgary, AB, Canada; Trevor DeVries, University of Guelph, Guelph, ON, Canada; Jean-Philippe Roy and Luc Des Côteaux,
University of Montreal, Montreal, QC, Canada; and Kristen Reyher, University of Prince Edward Island, Charlottetown, PE, Canada) who participated in the data collection. This research was financed by the Natural Sciences and Engineering Research Council of Canada (Ottawa, ON, Canada), Alberta Milk (Edmonton, AB, Canada), Dairy Farmers of New Brunswick (Sussex, NB, Canada), Dairy Farmers of Nova Scotia (Lower Truro, NS, Canada), Dairy Farmers of Ontario (Mississauga, ON, Canada) and Dairy Farmers of Prince Edward Island (Charlottetown, PE, Canada), Novalait Inc. (Quebec City, QC, Canada), Dairy Farmers of Canada (Ottawa, ON, Canada), Canadian Dairy Network (Guelph, ON, Canada), Agriculture and AgriFood Canada (Ottawa, ON, Canada), Public Health Agency of Canada (Ottawa, ON, Canada), Technology PEI Inc. (Charlottetown, PE, Canada), Université de Montréal (Montreal, QC, Canada) and University of Prince Edward Island, through the Canadian Bovine Mastitis Research Network (Saint-Hyacinthe, QC, Canada). 


\section{REFERENCES}

Barkema, H. W., H. A. Deluyker, Y. H. Schukken, and T. J. Lam. 1999. Quarter-milk somatic cell count at calving and at the first six milkings after calving. Prev. Vet. Med. 38:1-9.

Bradley, A. J., and M. J. Green. 2000. A study of the incidence and significance of intramammary enterobacterial infections acquired during the dry period. J. Dairy Sci. 83:1957-1965.

Bradley, A. J., and M. J. Green. 2004. The importance of the nonlactating period in the epidemiology of intramammary infection and strategies for prevention. Vet. Clin. North Am. Food Anim. Pract. 20:547-568.

Canadian Dairy Information Centre. 2012. Enrollments on Milk Recording. Accessed Apr. 25, 2012. http://www.infolait.gc.ca/ index_e.php?s1=dff-fcil\&s2=mrr-pcle\&s3=dhi-agbl\&page $=$ emripcl.

Cook, N. B., T. B. Bennett, K. M. Emery, and K. V. Nordlund. 2002 Monitoring nonlactating cow intramammary infection dynamics using DHI somatic cell count data. J. Dairy Sci. 85:1119-1126.

Dohoo, I., S. Andersen, R. Dingwell, K. Hand, D. Kelton, K. Leslie, Y. Schukken, and S. Godden. 2011a. Diagnosing intramammary infections: Comparison of multiple versus single quarter milk samples for the identification of intramammary infections in lactating dairy cows. J. Dairy Sci. 94:5515-5522.

Dohoo, I., W. Martin, and H. Stryhn. 2009. Veterinary Epidemiologic Research. 2nd ed. VER Inc., Charlottetown, Prince Edward Island, Canada.

Dohoo, I. R., and K. E. Leslie. 1991. Evaluation of changes in somatic cell counts as indicators of new intramammary infections. Prev. Vet. Med. 10:225-237.

Dohoo, I. R., J. Smith, S. Andersen, D. F. Kelton, and S. Godden. 2011b. Diagnosing intramammary infections: Evaluation of definitions based on a single milk sample. J. Dairy Sci. 94:250-261.

Dufour, S., H. W. Barkema, L. DesCoteaux, T. J. DeVries, I. R. Dohoo, K. Reyher, J. P. Roy, and D. T. Scholl. 2010. Development and validation of a bilingual questionnaire for measuring udder health related management practices on dairy farms. Prev. Vet. Med. 95:74-85.

Green, M. J., L. E. Green, G. F. Medley, Y. H. Schukken, and A. J. Bradley. 2002. Influence of dry period bacterial intramammary infection on clinical mastitis in dairy cows. J. Dairy Sci. 85:25892599.

Halasa, T., M. Nielen, A. C. Whist, and O. Osteras. 2009. Metaanalysis of dry cow management for dairy cattle. Part 2. Cure of existing intramammary infections. J. Dairy Sci. 92:3150-3157.

Hogan, J. S., R. N. Gonzalez, R. J. Harmon, S. C. Nickerson, S. P. Oliver, J. W. Pankey, and K. L. Smith. 1999. Laboratory Handbook on Bovine Mastitis. Natl. Mastitis Counc., Madison, WI.

Mollenhorst, H., P. P. van der Tol, and H. Hogeveen. 2010. Somatic cell count assessment at the quarter or cow milking level. J. Dairy Sci. 93:3358-3364.

Pantoja, J. C., C. Hulland, and P. L. Ruegg. 2009. Dynamics of somatic cell counts and intramammary infections across the dry period. Prev. Vet. Med. 90:43-54.

Reyher, K. K., S. Dufour, H. W. Barkema, L. Des Coteaux, T. J. Devries, I. R. Dohoo, G. P. Keefe, J. P. Roy, and D. T. Scholl. 2011. The National Cohort of Dairy Farms - A data collection platform for mastitis research in Canada. J. Dairy Sci. 94:1616-1626.

Sargeant, J. M., K. E. Leslie, J. E. Shirley, B. J. Pulkrabek, and G. H. Lim. 2001. Sensitivity and specificity of somatic cell count and California Mastitis Test for identifying intramammary infection in early lactation. J. Dairy Sci. 84:2018-2024.

Schukken, Y. H., D. J. Wilson, F. Welcome, L. Garrison-Tikofsky, and R. N. Gonzalez. 2003. Monitoring udder health and milk quality using somatic cell counts. Vet. Res. 34:579-596.

Smith, K. L., D. A. Todhunter, and P. S. Schoenberger. 1985. Environmental pathogens and intramammary infection during the dry period. J. Dairy Sci. 68:402-417.

Sol, J., O. C. Sampimon, J. J. Snoep, and Y. H. Schukken. 1994. Factors associated with bacteriological cure after dry cow treatment of subclinical staphylococcal mastitis with antibiotics. J. Dairy Sci. $77: 75-79$

Sol, J., O. C. Sampimon, J. J. Snoep, and Y. H. Schukken. 1997. Factors associated with bacteriological cure during lactation after therapy for subclinical mastitis caused by Staphylococcus aureus. J. Dairy Sci. 80:2803-2808.

Todhunter, D. A., K. L. Smith, J. S. Hogan, and P. S. Schoenberger. 1991. Gram-negative bacterial infections of the mammary gland in cows. Am. J. Vet. Res. 52:184-188. 